\title{
Correlation of Lipid Profile and Risk of Developing Type 2 Diabetes Mellitus in 10-14 Year Old Children
}

\author{
Nusrath M. Habiba ${ }^{a}$ Kimberly G. Fulda ${ }^{b}$ Riyaz Basha ${ }^{a}$ Deep Shah ${ }^{a}$ \\ Shane Fernando ${ }^{a}$ Bao Nguyen ${ }^{c}$ Yi Xiong $^{c}$ Susan F. Franks ${ }^{b}$ Sarah J. Matches ${ }^{a}$ \\ Richard D. Magie $\quad$ W. Paul Bowman ${ }^{\mathrm{a}}$ \\ aDepartment of Pediatrics, bepartment of Family Medicine, 'Texas College of Osteopathic Medicine, \\ University of North Texas Health Science Center, Fort Worth, TX, USA
}

\section{Key Words}

Type 2 diabetes mellitus $\bullet$ Lipid profiles $•$ Obesity $\bullet$ Children

\begin{abstract}
Background/Aims: The role of lipid profile in predicting the risk of Type 2 diabetes mellitus (T2DM) in children is not clearly established. Our aim is to screen non-diabetic children aged 10-14 years for risk of developing T2DM and evaluate the association of abnormal lipids and socioeconomic status (SES). Methods: Data on race/ethnicity, family history, body mass index percentile, blood pressure and presence of neck pigmentation (acanthosis nigricans) were collected from 149 non-diabetic children. Using these factors, children were classified into low risk ( $<3$ risk factors) and high risk ( $\geq 3$ risk factors) groups. Logistic regression model and chi-square tests were used to evaluate the association of blood lipid profile and demographic variables. Independent $t$-test was used to compare the ratio of Total Cholesterol (TC) and High Density Lipids (HDL) with T2DM risk. Results: $60 \%$ of children were at high risk for developing T2DM. HDL $(p<0.001)$, triglycerides $(p=0.02)$ and TC/HDL ratio $(p<.001)$ were significantly abnormal in high risk group. Low SES showed a marginal association with high risk group. There were no gender or age differences between high and low risk groups. Conclusions: The significant determinants associated with high risk group were modifiable factors providing an opportunity for early intervention and prevention.

\section{Introduction}

Obesity is a complex condition and highly associated with dietary and nutritional issues. More than one third of adults and $17 \%$ of children are obese in the United States $[1,2]$. Obesity leads to multiple health complications including type 2 diabetes mellitus (T2DM), cardiovascular diseases, cancer, musculoskeletal diseases, liver, respiratory, gynecological

Nusrath M. Habiba, MD, FAAP Associate Professor and Assistant Clerkship Director
Department of Pediatrics, University of North Texas Health Science Center Fort Worth, Texas (USA)

Tel. +1-817-735-2363, Fax +1-817-735-2653, E Mail Nusrath.Habiba@unthsc.edu 
and mental diseases [3-6]. The incidence of T2DM has substantially increased over the past 20 years [7]. Most of the T2DM patients are overweight or obese at the time of diagnosis [8]. T2DM is characterized by hyperglycemia, insulin resistance, and relative impairment in insulin secretion [9]. Traditionally, T2DM was considered to be an adult onset disease, as it used to be limited to older ages[10]. Recently, there has been an increased prevalence of this disease in children and adolescents $[9,11]$. As younger children are becoming obese and remaining obese throughout childhood and adolescent years, diabetes and its complications are occurring earlier in life. According to National Diabetes Statistics, 12.3\% (28.9 million) of the United States population under the age of 20 are currently believed to have diabetes [12]. The prevalence of T2DM among children has dramatically increased ( $>30 \%)$ between 2001 and 2009 [13].

Based on current disease progression, the American Diabetes Association (ADA) has developed guidelines for screening T2DM in children which include both invasive and noninvasive markers. It recommends testing children 10 years or older if their body mass index (BMI) is $>85$ percentile for age and gender and they have two of the following risk factors: 1. Race/ethnicity (American Indian, African American, Hispanic, Asian/Pacific Islander), 2. Positive family history of T2DM in a first or second degree relative and 3. Signs or conditions associated with insulin resistance (e.g., acanthosis nigricans, hypertension, dyslipidemia, polycystic ovarian syndrome) [8]. Recently, Peterson et al. [14] conducted a study to determine the prevalence of T2DM risk factors in children (4 to 14 years) from rural low-income families using a non-invasive screening method incorporating ADA recommendations. In our study, we have evaluated children aged 10-14 years for the risk of T2DM using a similar method in an urban population.

Dyslipidemia is considered to be a risk factor for the development of T2DM $[15,16]$. The experimental studies for developing novel therapeutic strategies for diabetes often targeted on correcting dyslipidemia [17-19]. The expert panel of the National Heart, Lung and Blood Institute (NHLBI) recommended universal lipid screening for children between 9 to 11 years in 2011 and this has been endorsed by the American Academy of Pediatrics (AAP) [20]. This guideline was developed to provide early detection of risks and promote cardiovascular health. Atherosclerotic cardiovascular disease (CVD) is the leading cause of death in adults in North America [12]. Even though CVD is rare in children, the risk factors and the risk behaviors can still be present in children [6]. The routine lipid profile ordered by clinicians includes total cholesterol (TC), high density lipoprotein (HDL) and triglycerides (TG). From these values, low density lipoprotein (LDL), TC/HDL ratio and non-HDL cholesterol are calculated for clinical assessment. Even though the AAP has recommended universal lipid screening in 9 to11 year old children, there are no established guidelines on how to utilize and interpret these results to predict the risk of T2DM. Numerous studies have suggested the link between dyslipidemia and the risk of getting T2DM; however, none of these studies have performed a detailed analysis to establish an association of abnormal lipids with T2DM risk. Assessing the risk early allows prompt interventions including the adjustments in life style and change in diet to prevent T2DM. It is especially critical and cost effective to determine such risk during childhood.

\section{Materials and Methods}

\section{Study Location and Patient enrollment}

It is a cross-sectional research study conducted at the University of North Texas Health Science Center (UNTHSC) outpatient clinics in Fort Worth, which is the fifth largest city in Texas. Ninety five percent of the children were recruited from the Pediatric Clinic which is a major outpatient pediatric facility in Fort Worth. It was conducted using a protocol approved by the Institutional Review Board (IRB) of UNTHSC, Fort Worth, Texas. The participants were 10-14 years old, enrolled from representative races and ethnicities attending the clinics. Subjects with chronic diseases (cystic fibrosis, genetic syndromes, hypo or hyper- thyroid conditions, adrenal diseases), already diagnosed with diabetes or who had consumed oral corticosteroids 


\section{Cellular Physiology Cell Physiol Biochem 2016;39:1695-1704 \begin{tabular}{l|l|l} 
and BOI: 10.1159/000447870 & $\begin{array}{l}\text { C } 2016 \text { The Author(s). Published by S. Karger AG, Basel } \\
\text { www.karger.com/cpb }\end{array}$
\end{tabular}}

Habiba et al.: Lipid Profiles in Children with Diabetes Risk

within the past one year were excluded from the study. Only non-diabetic subjects were enrolled for this study. Typically, blood glucose measuring 100 to $125 \mathrm{mg} / \mathrm{dL}$ (fasting) or 140 to $200 \mathrm{mg} / \mathrm{dL}$ (random) are considered as elevated levels in children [21]. Blood glucometer (Bayer Breeze 2 Blood glucose monitoring system) was used to determine the blood glucose levels and the children with glucose levels $>125 \mathrm{mg} / \mathrm{dL}$ (fasting) or $>200 \mathrm{mg} / \mathrm{dL}$ (random) were excluded from the study (14). Children with elevated blood glucose ( $\geq 100$ to $125 \mathrm{mg} / \mathrm{dL}$ fasting or $\geq 140$ to $200 \mathrm{mg} / \mathrm{dL}$ random) were included in the study and designated as having elevated glucose levels. During the study period 469 children were screened but due to exclusions, the study was completed with 153 participants.

\section{Data Collection}

All participants and their parents or legal guardians had signed IRB approved participant assent form or parent/legal guardian consent form prior to patient enrollment. The parent or legal guardian then completed the study related questionnaire providing the demographic information such as date of birth, gender, race/ethnicity, socioeconomic status (SES) and information about family history (first or second degree relatives) related to T2DM. Low SES was determined using two proxy variables, utilization of free/ reduced-cost school lunches and household use of food stamps.

General clinical measurements such as height, weight, and blood pressure (average of two readings) were recorded for all participants. BMI percentile was calculated for age and gender of the subjects and the neck inspection was done by the clinic provider to identify the presence of posterior cervical acanthosis nigricans - dark pigmentation of the skin creases on the back of the neck (AN).

Blood samples were drawn at Quest Diagnostics (located adjacent to the Pediatric Clinic) and tested for lipid profile (TC, HDL, LDL, non-HDL, TG and TC/HDL ratio) in all participants. Abnormal values (TC: $\geq 170 \mathrm{mg} / \mathrm{dL} ; \mathrm{HDL}: \leq 40 \mathrm{mg} / \mathrm{dL} ; \mathrm{LDL}: \geq 110 \mathrm{mg} / \mathrm{dL} ;$ non-HDL: $\geq 120 \mathrm{mg} / \mathrm{dL} ; \mathrm{TG}: \geq 90 \mathrm{mg} / \mathrm{dL}$ ) were determined according to established criteria [Cholesterol Levels: Expert Panel, National Cholesterol Education Program (NCEP); non-HDL values: Bogalusa Heart Study].

\section{Identifying 'Low Risk' and 'High Risk' groups}

The risk of children developing T2DM was determined using noninvasive measures [14]. The five risk factors used were (1) BMI percentile $>85$ for age and gender, (2) High blood pressure (history of hypertension or average systolic or diastolic blood pressure reading at or above $95^{\text {th }}$ percentile for height and gender) [22, 23], (3) Presence of AN, (4) High-risk race/ethnicity (American Indian, African American, Hispanic, Asian/pacific islander) and (5) Positive family history of T2DM in a first or second degree relative. Children with less than three risk factors were categorized as 'Low Risk' group, while children with three or more risk factors were categorized as 'High Risk' group.

\section{Statistical Analysis}

Data were collected from 153 children over 18 months. After careful review of the data, four of them were excluded from the analysis because of missing values in one or more variables. The remaining 149 subjects were included in the analysis. Statistical analysis was performed using the Statistical Package for the Social Sciences (SPSS) version 21. The cross tabulations between T2DM risk (low and high) and lipid data, elevated blood glucose ( $\geq 100$ to $125 \mathrm{mg} / \mathrm{dL}$ fasting or $\geq 140$ to $200 \mathrm{mg} / \mathrm{dL}$ random), and demographic variables were performed by chi-square tests to determine the variables significantly associated with T2DM risk. An independent- $t$ test was used to compare the TC/HDL ratio between low risk and high risk groups. Finally, a logistic regression model was conducted with all lipid indices, elevated blood glucose and demographic variables to predict the risk of T2DM. A forward-stepwise model selection method was applied to keep only the significant variables in the final model. Odds ratio and their $95 \%$ confidence interval (CI) for each significant predictor were also obtained.

\section{Results}

Demographic Analysis

Race/ethnic background, gender and age group of the participants were analyzed. The majority of participants were Hispanics (58.4\%), followed by African Americans (26.2\%), Caucasians $(10.1 \%)$ and others (5.4\%). The female subjects were slightly more numerous 
$(52.3 \%)$ than the male subjects $(47.7 \%)$. The details of the demographics are given in Table 1.

Evaluation of low risk and high risk groups

The total number of children under 'high risk' or 'low risk' categories, frequency and percentage of each risk factor in the study group are given in Table 2. Overall, the data show an increasing number of children with one to four risk factors $(1: 13.4 \% ; 2: 24.2 \% ; 3: 24.8 \%$; 4: $32.2 \%$ ), while the children with none or all five risk factors were minimal in number (2.7\%). In total, 89 subjects were identified as 'high risk' and 60 subjects as low risk.

Prevalence of various risk factors in low risk and high risk groups

The prevalence of each risk factor in relation to risk group was evaluated and the results are shown in Table 3 . The high blood pressure, BMI percentile $\left(>85^{\text {th }}\right.$ percentile for age and gender), and AN were highly correlated with the high risk group when compared to race/ethnicity and positive family history. One hundred percent of the children with high blood pressure, $94 \%$ with BMI $>85^{\text {th }}$ percentile, $88.5 \%$ with $\mathrm{AN}, 66 \%$ with high risk race/ethnicity, and $71 \%$ with positive family history were in the high risk category.

Lipid profile and blood glucose levels

The results of lipid profile including TC, HDL, LDL, non-HDL and TG were analyzed in all participants. Abnormal levels of (low) HDL $(p<0.001)$ and (elevated) TG $(p=0.02)$ were significantly greater in the high risk group showing a strong correlation with T2DM risk. Abnormality of other lipid markers such as TC, LDL, non-HDL and elevated blood glucose levels were not significantly different among high risk and low risk groups (Table 4).

The box-plot showing the distribution of the TC/HDL ratio among low risk and high risk groups is presented in Figure 1. Using independent $t$-test, statistical analysis revealed the average TC/HDL ratio was significantly higher in the high risk group than low risk group $(0.87$ vs $0.70, t=3.93$, $p<0.001$ ).

Demographics and T2DM risk analysis

Only the low SES was marginally $(p=0.07)$ correlated with high risk group. Other variables, gender and age were not different ( $p=0.64$ and 0.46 respectively for gender and age) among low risk and high risk groups (Table 5).
Table 1. Demographics of the children participated in the study. The demographic information representing the race/ethnicity of participants. The majority of participants were Hispanics (58.4\%), followed by African Americans (26.2\%), Caucasians (10.1\%) and others (5.4\%)

\begin{tabular}{lll}
\hline $\begin{array}{l}\text { Demographic } \\
\text { Variables }\end{array}$ & $\begin{array}{l}\text { Frequency } \\
\mathrm{N}=149\end{array}$ & Percentage \\
\hline $\begin{array}{l}\text { Race/ethnicity } \\
\text { White/Caucasian }\end{array}$ & 15 & 10.1 \\
Black/African-American & 39 & 26.2 \\
Hispanic & 87 & 58.4 \\
Multiracial & 7 & 4.7 \\
Other & 1 & 0.7 \\
& & \\
Gender & & \\
Male & 71 & 47.7 \\
Female & 78 & 52.3 \\
& & \\
Age & & \\
10 & 36 & 24.2 \\
11 & 29 & 19.5 \\
13 & 34 & 22.8 \\
14 & 30 & 20.1 \\
\hline
\end{tabular}

Table 2. Frequency of risk factors and classification of risk groups

\begin{tabular}{cll}
\hline Number of Risk Factors & $\mathrm{n}(\%)$ & Risk Category \\
\hline 0 & $4(2.7)$ & Low Risk \\
1 & $20(13.4)$ & Low Risk \\
2 & $36(24.2)$ & Low Risk \\
3 & $37(24.8)$ & High Risk \\
4 & $48(32.2)$ & High Risk \\
5 & $4(2.7)$ & High Risk \\
& & \\
$<3$ & $60(40)$ & Low Risk \\
$\geq 3$ & $89(60)$ & High Risk \\
\hline
\end{tabular}


Table 3. Status of risk factors among 'Low Risk' and 'High Risk' groups. ${ }^{1}$ Body Mass Index above $85^{\text {th }}$ percentile for age and gender. ${ }^{2}$ History of hypertension or average systolic or diastolic blood pressure reading at or above $95^{\text {th }}$ percentile for height and gender. 3 Posterior cervical Acanthosis nigricans. ${ }^{4}$ High risk race/ethnicity includes American Indian, African American, Hispanic, Asian/ Pacific islander (American Diabetes Association, 2000). ${ }^{5}$ Positive family history of T2DM in first or second degree relatives. anformation for one subject is missing. As this subject has only one other risk factor, it will not affect the high risk and low risk status. Hence, it was included in the analysis

Table 4. Status of lipid indices and blood glucose levels among Low Risk and High Risk groups. Abbreviations: TC - Total Cholesterol; LDL - Low density Lipoprotein; HDL - High density Lipoprotein. Abnormal Values: TC $(\geq 170 \mathrm{mg} /$ $\mathrm{dL})$, LDL ( $\geq 110 \mathrm{mg} / \mathrm{dL}), \mathrm{HDL}(\leq 40$ $\mathrm{mg} / \mathrm{dL})$, non-HDL $(\geq 120 \mathrm{mg} / \mathrm{dL})$ and TG ( $\geq 90 \mathrm{mg} / \mathrm{dL})$ [Source: Cholesterol Levels: Expert Panel, National Cholesterol Education Program (NCEP); non-HDL values: Bogalusa Heart Study]. ${ }^{1}$ glucose levels $<100 \mathrm{mg} / \mathrm{dL}$ (fasting) or $<140 \mathrm{mg} / \mathrm{dL}$ (random). ${ }^{2}$ glucose levels 100 to $125 \mathrm{mg} / \mathrm{dL}$ (fasting) or 140 to $200 \mathrm{mg} / \mathrm{dL}$ (random). * Significant at .05 level, ${ }^{* *}$ significant at .01 level

\begin{tabular}{|c|c|c|c|}
\hline Risk Factors & $\begin{array}{l}\text { Total } \\
\text { Subjects }(n=149)\end{array}$ & $\begin{array}{l}\text { Low Risk } \\
\mathrm{n}(\%)\end{array}$ & $\begin{array}{l}\text { High Risk } \\
\mathrm{n}(\%)\end{array}$ \\
\hline \multicolumn{4}{|c|}{ BMI percentile $>85^{1}$} \\
\hline No & 66 & $55(83.3)$ & $11(16.7)$ \\
\hline Yes & 83 & $5(6)$ & $78(94)$ \\
\hline \multicolumn{4}{|c|}{ High blood pressure ${ }^{2}$} \\
\hline No & 141 & $60(42.5)$ & $81(57.5)$ \\
\hline Yes & 8 & $0(0)$ & $8(100)$ \\
\hline \multicolumn{4}{|c|}{ Acanthosis nigricans ${ }^{3}$} \\
\hline No & 71 & $51(71.8)$ & $20(28.2)$ \\
\hline Yes & 78 & $9(11.5)$ & $69(88.5)$ \\
\hline \multicolumn{4}{|c|}{ High risk race/ethnicity 4} \\
\hline No & 15 & $14(93.3)$ & $1(6.7)$ \\
\hline Yes & 134 & $46(34.3)$ & $88(65.7)$ \\
\hline \multicolumn{4}{|c|}{$\begin{array}{l}{ }^{a} \text { Positive family history } \\
\text { of } T 2 D M^{5}\end{array}$} \\
\hline No & 36 & $27(75)$ & $9(25)$ \\
\hline Yes & 112 & $32(28.6)$ & $80(71.4)$ \\
\hline
\end{tabular}

\begin{tabular}{lllll}
$\mathrm{TC}$ & & & \\
$<170 \mathrm{mg} / \mathrm{dL}$ & 45 & 68 & 039 & .84 \\
$\geq 170 \mathrm{mg} / \mathrm{dL}$ & 15 & 21 & & \\
$\mathrm{LDL}$ & & & & \\
$<110 \mathrm{mg} / \mathrm{dL}$ & 56 & 78 & 1.28 & .26 \\
$\geq 110 \mathrm{mg} / \mathrm{dL}$ & 4 & 11 & & \\
$\mathrm{HDL}$ & & & & \\
$<40 \mathrm{mg} / \mathrm{dL}$ & 5 & 31 & & \\
$\geq 40 \mathrm{mg} / \mathrm{dL}$ & 55 & 58 & & \\
Non HDL & & & & \\
$<120 \mathrm{mg} / \mathrm{dL}$ & 48 & 67 & & \\
$\geq 120 \mathrm{mg} / \mathrm{dL}$ & 12 & 22 & & \\
Triglycerides & & & & \\
$<90 \mathrm{mg} / \mathrm{dL}$ & 33 & 31 & & \\
$\geq 90 \mathrm{mg} / \mathrm{dL}$ & 27 & 58 & & \\
& & & & \\
Blood Glucose Levels & & & & \\
& & & & \\
Normal ${ }^{1}$ & 56 & 12 & & \\
Elevated & 4 & & & \\
\hline
\end{tabular}

\section{Studying the significant predictors}

The logistic regression analysis with forward-stepwise model selection algorithm was used to identify predictors for assessing the risk of T2DM (Table 6). This model detected three variables, HDL, TC/HDL ratio, and low SES. TG was no longer significant when modeled together with the other lipid indices. TG levels were highly correlated with HDL and TC/HDL ratio, therefore, the variance in outcome variable (high risk/low risk) explained by TG was overlapping with the variance explained by HDL or/and TC/HDL. 
Fig. 1. Cholesterol ratio: Median Total Cholesterol/HDL- Cholesterol Ratio in children with low $(\mathrm{N}=60)$ and high risk $(\mathrm{N}=89)$ of developing Type 2 Diabetes Mellitus. For the box plot, the box represents the interquartile range $\left(25^{\text {th }}-75^{\text {th }}\right.$ percentiles $)$, and the line in the middle of the box represents the median value. The brackets extending from the box represent the lower and upper adjacent values. TC/HDL ratio is significantly higher in high risk group (0.87 VS 0.70, $t=3.93, p<0.001$ ).

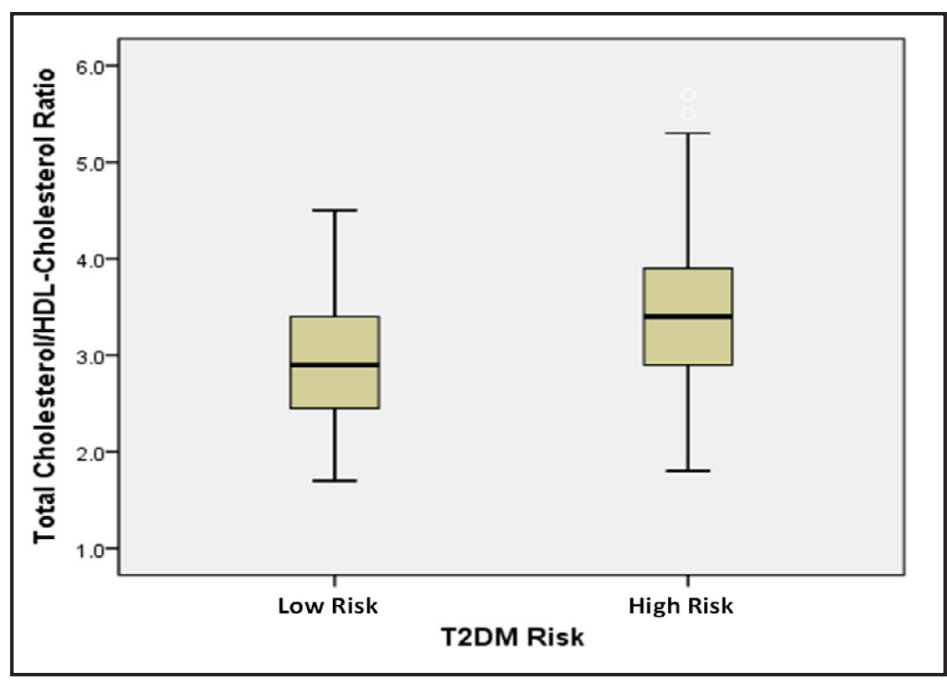

According to the calculation of odds ratio in Table 6 , the subjects with low HDL were $4.14 \quad$ (95\%CI: 1.32 12.98) times more likely to be categorized under high risk than the subjects with high HDL if their SES and TC/HDL were the same. The subjects with high TC/HDL ratio were 1.79 (95\% CI: 1.04-3.06) times more likely to have T2DM risk than those with low TC/HDL if their SES and HDL were same. In addition, low SES group was 2.60 (95\% CI: 1.03-6.57) times more likely to have T2DM risk than high SES group if their HDL and TC/HDL were the same.

\section{Discussion}

The incidence of T2DM and associated complications has been increasing in children, adolescents and adults [24]. Hence, identifying children at risk for T2DM at an early age would allow timely life style modification and disease preventing interven-

Table 5. The relationship between each demographic variable in Low Risk and High Risk groups. 1 Low socioeconomic Status was determined using two proxy variables: utilization of Free/reduced-cost school lunches and household use of food stamps * Significant at .05 level

\begin{tabular}{lllll}
\hline $\begin{array}{l}\text { Demographic } \\
\text { Variables }\end{array}$ & Low Risk & High Risk & Chi-square & $p$-value \\
\hline $\begin{array}{l}\text { Gender } \\
\text { Male }\end{array}$ & 30 & 41 & .22 & .64 \\
Female & 30 & 48 & & \\
& & & & \\
Socioeconomic Status & & & & \\
Low & 44 & 76 & 3.33 & .07 \\
Not Low & 16 & 13 & & \\
& & & & \\
Age & 11 & 25 & 3.65 & .46 \\
10 & 15 & 14 & & \\
11 & 12 & 22 & & \\
12 & 13 & 17 & & \\
13 & 9 & 11 & & \\
14 & & & & \\
\hline
\end{tabular}

Table 6. Significant predictors identified using forward stepwise Logistic Regression model for risk of developing T2DM in 10-14 year old Children (Odds Ratio and 95\% Confidence Interval). $\beta$-coefficient, S.E. - standard error, OR indicates likelihood of risk of developing T2DM, CI - Confidence Interval, *significant at .05 level

\begin{tabular}{llllll}
\hline Predictors & $\beta$ & S.E. & Wald & p-value & Odds Ratio (95\%CI) \\
\hline Intercept & -2.48 & .918 & 7.28 & .007 & \\
HDL & 1.42 & .58 & 5.91 & $.015^{*}$ & $4.14(1.32-12.98)$ \\
SES & .96 & .47 & 4.08 & $.043^{*}$ & $2.60(1.03-6.57)$ \\
TC/HDL ratio & .58 & .28 & 4.43 & $.035^{*}$ & $1.79(1.04-3.06)$ \\
\hline
\end{tabular}
tions. It has been estimated that about 8.1 million people with T2DM are undiagnosed, many of whom are children [8]. In this study, only children with blood glucose in non-diabetic range were recruited to determine the risk status. Since the onset of T2DM for children is usually at or above the age 
of 10 [8], screening children at 10 to 14 years could be beneficial and cost effective for early identification of risk. We have carefully selected the exclusion criteria to ensure the abnormal glucose and lipid values found in our subjects were not due to other disease processes. To keep our study minimally invasive, we used blood glucometer testing instead of fasting plasma glucose to identify non diabetic children.

The ADA recommended screening criteria for children aged 10 years and above have some limitations. The major drawbacks are assessing the risk using the factors which involve invasive methods, for example, looking for signs or conditions associated with insulin resistance[8]. Children belonging to low SES/minorities are at high risk for developing T2DM but often lack access to preventive health checkups and depend on routine screening at schools. In our study, risk factors were identified using a modified ADA protocol using non-invasive criteria [14]. Only the posterior cervical region was inspected for AN. Other intertriginous areas such as the axillae were not examined. We have not included polycystic ovarian syndrome as a risk factor because it involves detailed history, physical examination and invasive lab tests. These strategies make the evaluation easier and will allow larger number of children to be screened in schools and other public places. Due to the strong association of the five risk factors to T2DM, it is reasonable to conclude that screening methods adopted in this study have accurately stratified low risk and high risk groups [22, 25-30].

As presented in Table 1 , this cross sectional study has a reasonable sample size (149) representing a diverse race/ethnicity. The participants are predominantly $(\sim 80 \%)$ ethnic minorities (Hispanics and African Americans) from urban areas. The demographic information of the subjects recruited to this study is in agreement with the distribution of various race/ethnic populations who typically visit our clinics.

The number of Hispanic children and adolescents diagnosed with T2DM has been substantially increasing in recent years [31]. The fact sheet (AHRQ Pub. No. 02-P007) released by the United States Department of Health and Human Services (HHS) stated that African Americans are $1.4-2.2$ times more likely to be diagnosed with T2DM. Due to the high percentage $(\sim 80 \%)$ of Hispanic and African American subjects in this study, it is possible that a significant number of participants (89) are in the high risk category.

T2DM is a multifactorial disease. It is believed that both genetic and environmental factors play a role in developing the disease. The chance of an identical twin to develop T2DM is approximately $80 \%$, if the other twin is a known diabetic [10]. The genetic basis is very complicated and poorly understood. Interestingly, among the five risk factors tested in the current study, the modifiable factors such as high BMI percentile, high blood pressure and AN were highly correlated with the high risk group as compared to the non-modifiable risk factors (race/ethnicity and positive family history) (Table 3). These results clearly indicate that T2DM can be considered as a potentially preventable disease in children and onset can be delayed in adults.

The primary causes for high BMI and abnormal lipids are attributed to poor diet and sedentary life style. Animal and human studies have shown that high fat diet alone leads to hyperinsulinemia, high blood pressure and kidney damage [32]. Molecular mechanisms showing an association of excessive lipid deposition with insulin resistance is well established $[33,34]$. A retrospective study in Mexican children demonstrated positive correlation between elevated BMI and abnormal lipid profiles [35]. Studies on adolescents revealed similar results showing a relationship between lipid profile and risk of diabetes [36-38]. TC/HDL ratio is used to predict the risk of heart disease in adults. A ratio below 3.5:1 is considered good and a higher ratio forecasts higher risk for heart disease. Even though an association of high TC/HDL ratio and T2DM risk has been proposed in some research studies in adults $[39,40]$, such association has not been shown in children. In our study TC/HDL ratio was significantly elevated in high risk group suggesting a strong association of elevated TC/HDL ratio with risk of developing T2DM.

One of the most important findings of this study was the determination of significant predictors for T2DM risk using the logistic regression model. Low HDL is the most powerful 
predictor $(p=0.015$; odds ratio $=4.14)$ followed by high TC/HDL ratio $(p=0.035$; odds ratio: 1.79) and low SES ( $p=0.043$; odds ratio: 2.6$)$. In the United States, it is noticeable that SES disparity exists among different race/ethnicity groups [41, 42]. Such disparity could potentially explain the correlation between low SES and T2DM risk noticed in this study.

Obesity is a growing health concern world-wide, surpassing other epidemic diseases such as AIDS and malnutrition [43, 44]. Diabetes and cardiovascular disease (CVD) are the top obesity-related health complications that affect both children and adults [44]. There is some overlap of risk factors among these two diseases. Obesity, high TG, low HDL and hypertension are all considered cardiometabolic risk factors. The presence of two or more of these factors increases the risk of pre-diabetes [45]. Our research study is in agreement with this statement. In addition, a high TC/HDL ratio is also one of the predictors for high risk of developing T2DM. This finding emphasizes the importance of universal lipid screening in children for assessing the cardiovascular as well as T2DM risks allowing early interventions. The significant determinants associated with the high risk of T2DM - low HDL, high TG and TC/HDL ratio and low SES, are all modifiable factors. Hence, early interventions could potentially avoid health complications and unfavorable outcomes in later life.

\section{Acknowledgements}

This work is partially supported by a grant from the UNT Health Science Center, Fort Worth, TX. Authors thank Binky Bawa, MPH, Project Coordinator, for her assistance in recruiting the participants, consenting, screening and data collection and Feiming Li, PhD for assisting in data analysis. We also thank Dr. Jon Sivoravong for his support in recruiting subjects from the Seminary Family Medicine clinic. We also thank the participants and their parents for participating in the study.

\section{Ethical Approval}

All procedures performed in studies involving human participants were in accordance with the ethical standards of the institutional and/or national research committee and with the 1964 Helsinki declaration and its later amendments or comparable ethical standards.

\section{Disclosure Statement}

None declared.

\section{References}

1 Ogden CL, Carroll MD, Kit BK, Flegal KM: Prevalence of childhood and adult obesity in the United States, 2011-2012. JAMA 2014;311:806-814.

2 Lieb DC, Snow RE, DeBoer MD: Socioeconomic factors in the development of childhood obesity and diabetes. Clin Sports Med 2009;28:349-378.

3 Gallagher EJ, LeRoith D: Epidemiology and molecular mechanisms tying obesity, diabetes, and the metabolic syndrome with cancer. Diabetes Care 2013;36:S233-239.

4 Leddy MA, Power ML, Schulkin J: The impact of maternal obesity on maternal and fetal health. Rev Obstet Gynecol 2008;1:170-178. 


\section{Cellular Physiology Cell Physiol Biochem 2016;39:1695-1704 and Biochemistry \begin{tabular}{l|l} 
DOI: 10.1159/000447870 & (c) 2016 The Author(s). Published by S. Karger AG, Basel \\
www.karger.com/cpb
\end{tabular} \\ Habiba et al.: Lipid Profiles in Children with Diabetes Risk}

5 Wolin KY, Carson K, Colditz GA: Obesity and cancer. Oncologist 2010;15:556-565.

6 Berenson GS, Srinivasan SR, Bao W, Newman WP, 3rd, Tracy RE, Wattigney WA: Association between multiple cardiovascular risk factors and atherosclerosis in children and young adults. The bogalusa heart study. N Engl J Med 1998;338:1650-1656.

7 Ramachandran A, Mary S, Yamuna A, Murugesan N, Snehalatha C: High prevalence of diabetes and cardiovascular risk factors associated with urbanization in india. Diabetes Care 2008;31:893-898.

8 ADA: Type 2 diabetes in children and adolescents. American diabetes association. Diabetes Care 2000;23:381-389.

9 Williams DE, Cadwell BL, Cheng YJ, Cowie CC, Gregg EW, Geiss LS, Engelgau MM, Narayan KM, Imperatore G: Prevalence of impaired fasting glucose and its relationship with cardiovascular disease risk factors in us adolescents, 1999-2000. Pediatrics 2005;116:1122-1126.

10 van Tilburg J, van Haeften TW, Pearson P, Wijmenga C: Defining the genetic contribution of type 2 diabetes mellitus. J Med Genet 2001;38:569-578.

11 Pinhas-Hamiel 0, Zeitler P: The global spread of type 2 diabetes mellitus in children and adolescents. J Pediatr 2005;146:693-700.

12 Mozaffarian D, Benjamin EJ, Go AS, Arnett DK, Blaha MJ, Cushman M, de Ferranti S, Despres JP, Fullerton HJ, Howard VJ, Huffman MD, Judd SE, Kissela BM, Lackland DT, Lichtman JH, Lisabeth LD, Liu S, Mackey RH, Matchar DB, McGuire DK, Mohler ER, 3rd, Moy CS, Muntner P, Mussolino ME, Nasir K, Neumar RW, Nichol G, Palaniappan L, Pandey DK, Reeves MJ, Rodriguez CJ, Sorlie PD, Stein J, Towfighi A, Turan TN, Virani SS, Willey JZ, Woo D, Yeh RW, Turner MB, American Heart Association Statistics C, Stroke Statistics S: Heart disease and stroke statistics--2015 update: A report from the american heart association. Circulation 2015;131:e29-322.

13 Hwang YC, Ahn HY, Yu SH, Park SW, Park CY: Atherogenic dyslipidaemic profiles associated with the development of type 2 diabetes: A 3.1-year longitudinal study. Diabet Med 2014;31:24-30.

14 Peterson S, Sheffer S, Roth SL, Bennett PA, Lloyd L: Noninvasive screening for risk factors of type 2 diabetes in young, rural, caucasian children. J Sch Nurs 2010;26:301-309.

15 Carmena R: Type 2 diabetes, dyslipidemia, and vascular risk: Rationale and evidence for correcting the lipid imbalance. Am Heart J 2005;150:859-870.

16 Haffner SM, American Diabetes A: Management of dyslipidemia in adults with diabetes. Diabetes Care 2003;26 Suppl 1:S83-86.

17 Kondeti VK, Badri KR, Maddirala DR, Thur SK, Fatima SS, Kasetti RB, Rao CA: Effect of pterocarpus santalinus bark, on blood glucose, serum lipids, plasma insulin and hepatic carbohydrate metabolic enzymes in streptozotocin-induced diabetic rats. Food Chem Toxicol 2010;48:1281-1287.

18 Rajasekhar MD, Badri KR, Vinay Kumar K, Babu KR, Fatima SS, Sampath Kumar MT, Appa Rao C: Isolation and characterization of a novel antihyperglycemic protein from the fruits of momordica cymbalaria. J Ethnopharmacol 2010;128:58-62.

19 Bell DA, Watts GF: Contemporary and novel therapeutic options for hypertriglyceridemia. Clin Ther 2015;37:2732-2750.

20 Expert panel on integrated guidelines for cardiovascular health and risk reduction in children and adolescents: Summary report. Pediatrics 2011;128:S213-256.

21 American Diabetes A: Diagnosis and classification of diabetes mellitus. Diabetes Care 2004;27:S5-S10.

22 Weiss R, Dziura J, Burgert TS, Tamborlane WV, Taksali SE, Yeckel CW, Allen K, Lopes M, Savoye M, Morrison J, Sherwin RS, Caprio S: Obesity and the metabolic syndrome in children and adolescents. N Engl J Med 2004;350:2362-2374.

23 National High Blood Pressure Education Program Working Group on High Blood Pressure in Children and Adolescents: The fourth report on the diagnosis, evaluation, and treatment of high blood pressure in children and adolescents. Pediatrics 2004;114:555-576.

24 Chen L, Magliano DJ, Zimmet PZ: The worldwide epidemiology of type 2 diabetes mellitus--present and future perspectives. Nat Rev Endocrinol 2012;8:228-236.

25 Viner RM, Segal TY, Lichtarowicz-Krynska E, Hindmarsh P: Prevalence of the insulin resistance syndrome in obesity. Arch Dis Child 2005;90:10-14.

26 Muntner P, He J, Cutler JA, Wildman RP, Whelton PK: Trends in blood pressure among children and adolescents. JAMA 2004;291:2107-2113. 


\section{Cellular Physiology Cell Physiol Biochem 2016;39:1695-1704 \begin{tabular}{l|l|l|l|l}
\hline DOI: 10.1159/000447870 & $\begin{array}{l}\text { C) 2016 The Author(s). Published by S. Karger AG, Basel } \\
\text { www.karger.com/cpb }\end{array}$
\end{tabular}}

Habiba et al.: Lipid Profiles in Children with Diabetes Risk

27 Urrutia-Rojas X, Menchaca J: Prevalence of risk for type 2 diabetes in school children. J Sch Health 2006;76:189-194.

28 Drobac S, Brickman W, Smith T, Binns HJ: Evaluation of a type 2 diabetes screening protocol in an urban pediatric clinic. Pediatrics 2004;114:141-148.

29 Kong AS, Williams RL, Smith M, Sussman AL, Skipper B, Hsi AC, Rhyne RL, Clinicians RN: Acanthosis nigricans and diabetes risk factors: Prevalence in young persons seen in southwestern us primary care practices. Ann Fam Med 2007;5:202-208.

30 Chow EA, Foster H, Gonzalez V, McIver L: The disparate impact of diabetes on racial/ethnic minority populations. Clinical Diabetes 2012;30

31 Gregg EW, Zhuo X, Cheng YJ, Albright AL, Narayan KM, Thompson TJ: Trends in lifetime risk and years of life lost due to diabetes in the USA, 1985-2011: A modelling study. Lancet Diabetes Endocrinol 2014;2:867874.

32 Danda RS, Habiba NM, Rincon-Choles H, Bhandari BK, Barnes JL, Abboud HE, Pergola PE: Kidney involvement in a nongenetic rat model of type 2 diabetes. Kidney Int 2005;68:2562-2571.

33 Lukaszuk B, Kurek K, Miklosz A, Zendzian-Piotrowska M, Chabowski A: The role of pgc-1alpha in the development of insulin resistance in skeletal muscle - revisited. Cell Physiol Biochem 2015;37:2288-2296.

34 Fayyaz S, Japtok L, Kleuser B: Divergent role of sphingosine 1-phosphate on insulin resistance. Cell Physiol Biochem 2014;34:134-147.

35 Arjona-Villicaña RD, Herrera-Sánchez LF, Sumárraga-Ugalde CM, Alcocer-Gamboa MA: Relationship between body mass index and lipid profile in obese mexican children and adolescents: A retrospective analysis. Bol Med Hosp Infant Mex 2014;71:88-94.

36 Love-Osborne K, Butler N, Gao D, Zeitler P: Elevated fasting triglycerides predict impaired glucose tolerance in adolescents at risk for type 2 diabetes. Pediatr Diabetes 2006;7:205-210.

37 Lorenzo C, Hartnett S, Hanley AJ, Rewers MJ, Wagenknecht LE, Karter AJ, Haffner SM: Impaired fasting glucose and impaired glucose tolerance have distinct lipoprotein and apolipoprotein changes: The insulin resistance atherosclerosis study. J Clin Endocrinol Metab 2013;98:1622-1630.

38 Hwang YC, Ahn HY, Park SW, Park CY: Association of hdl-c and apolipoprotein a-i with the risk of type 2 diabetes in subjects with impaired fasting glucose. Eur J Endocrinol 2014;171:137-142.

39 Pandeya A, Sharma M, Regmi P, Basukala A, Lamsal M: Pattern of dyslipidemia and evaluation of non-HDL cholesterol as a marker of risk factor for cardiovascular disease in type 2 diabetes mellitus. Nepal Med Coll J 2012;14:278-282.

40 Subburam R, Manohar CR, Subramaniyam P, Sachithanantham S, Paul AV, Sankarapandian M: Dyslipidaemia among type 2 diabetes mellitus patients in a rural hospital in Erode district, Tamilnadu. J Indian Med Assoc 2013;111:10-13.

41 Anderson NB, Bulatao RA, Cohen B: in Anderson NB, Bulatao RA, Cohen B (eds): Critical perspectives on racial and ethnic differences in health in late life. Washington (DC), 2004.

42 Bulatao RA, Anderson NB: in Bulatao RA, Anderson NB (eds): Understanding racial and ethnic differences in health in late life: A research agenda. Washington (DC), 2004.

43 Lustig R, Preeyasombat C, Velasquez-Mieyer P: Treatment of childhood obesity; in Eugster E, Pescovitz 0 (ed): Pediatric Endocrinology: From Mechanisms to Management. Williams and Wilkins, 2004, pp 682714.

44 Velasquez-Mieyer P, Perez-Faustinelli S, Cowan PA: Identifying children at risk for obesity, type 2 diabetes, and cardiovascular disease. Diabetes Spectrum 2005;18:213-220.

45 Li C, Ford ES, Zhao G, Mokdad AH: Prevalence of pre-diabetes and its association with clustering of cardiometabolic risk factors and hyperinsulinemia among U.S. Adolescents: National health and nutrition examination survey 2005-2006. Diabetes Care 2009;32:342-347. 